\title{
Simple technique for recession of the inferior oblique muscle
}

W. E. GILLIES

Melbourne, Australia

A simple technique of recession of the inferior oblique muscle, which combines a high degree of safety with a graduated recession in the line of action of the muscle, is presented in this paper.

Eye surgeons have been divided on the choice of a weakening procedure for the inferior oblique muscle since White (I943) described recession of the inferior oblique. Some surgeons (Guibor, 1949; Colvin, I950; Fink, I951 ; Dunlap, I96o; ffooks, 1962) have considered recession to be the procedure of choice. Others (Scobee, 1952; Berke, I962; Dyer, I962; Costenbader and Kertesz, I964) have preferred myectomy, often because of the technical difficulty of performing recession. Still others have used both methods at different times (Brown, 1950; Anderson, 1959; Lyle and Wybar, 1967). It is probable that, if a simple method of recession of the inferior oblique muscle were available, mos\& surgeons would prefer recession because it is possible to obtain a graduated result.

\section{Technique}

General anaesthesia is used, an eye speculum is inserted and two episcleral fixation sutures are placed just outside the limbus at 12 and 6 o'clock respectively. A limbal conjunctival incision is then made from just above the horizontal meridian to a point between the lateral rectus and inferior rectus. This incision is then extended downwards and backwards, through Tenon's fascia and conjunctiva, from its lower end for about $5 \mathrm{~mm}$. (see Fig. I). A 6-o catgut is passed through the upper and lower corners of the conjunctival incision and left in place to enable easy resuturing of the conjunctiva.

The sclera is cleared by a blunt dissection in the floor of the incision and a squint hook is then passed downwards and backwards towards the floor of the orbit to pick up the inferior oblique muscle in the usual way. The fascia around the inferior oblique is buttonholed over the squint hook. Another squint hook is then passed in the reverse direction and the original squint hook removed.

With the squint hook under the inferior oblique muscle, another squint hook is placed under the insertion of the lateral rectus muscle from below. The two squint hooks are now separated to "put on the stretch" the fascial expansion from the inferior oblique to the lateral rectus insertion. If this fascial expansion is then divided with scissors it will lead directly down to the insertion of the inferior oblique muscle. The insertion of the inferior oblique may be brought into greater prominence by varying the tension on the squint hooks.

A whip stitch of 4.0 catgut is then inserted into the anterior aspect of the inferior oblique muscle near its insertion and the suture is locked. The amount of recession desired is marked on the sclera in the line of action of the inferior oblique muscle and the suture is inserted into the sclera at this point. The line of action of the inferior oblique is easy to determine while the muscle is in position as it is then fixed at its insertion and passes under the inferior rectus muscle where the sheath of the two muscles are fused (see Fig. 2). 
(2)

(I)

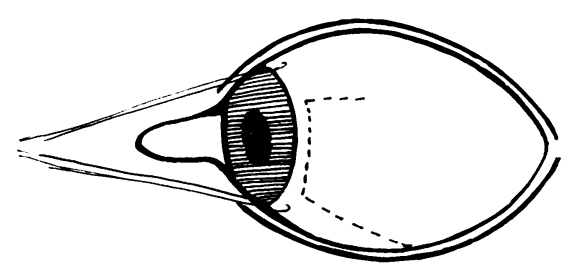

FIG. I Limbal incision with radial extension

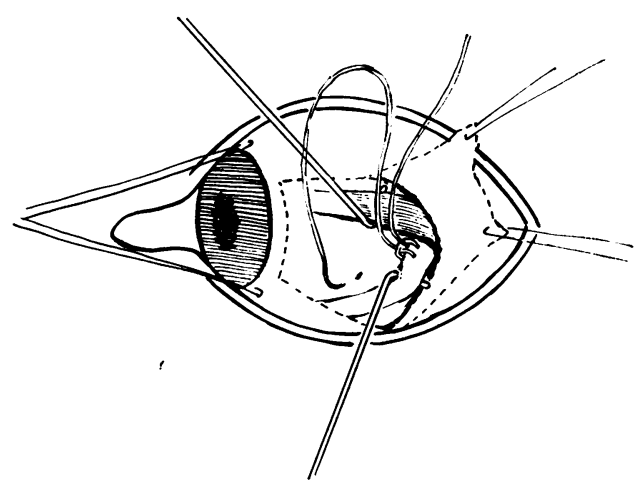

FIG. 2 Upper squint hook under lateral rectus. Lower squint hook under inferior oblique.

The fascial expansion from the inferior oblique to the lateral rectus has been divided.

$A$ whip stitch has been inserted into the inferior oblique at its insertion and this stitch has been inserted into the sclera at a measured site, before dividing the inferior oblique.

With the suture in position and held clear, the insertion of the inferior oblique muscle may now be severed with care, cutting only under direct vision. When the muscle has been separated from the globe, a leash of fascia remains, passing back towards the optic nerve. This may be severed under direct vision, cutting away from the globe (see Fig. 3).

The pre-placed suture is now tightened to bring the inferior oblique towards its new insertion. A single throw of the suture may be passed through the posterior aspect of the inferior oblique muscle to make it fit snugly to the sclera and the suture is tied (see Fig. 4).

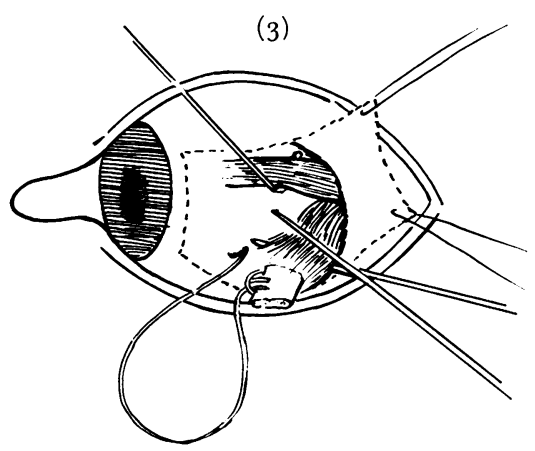

(4)

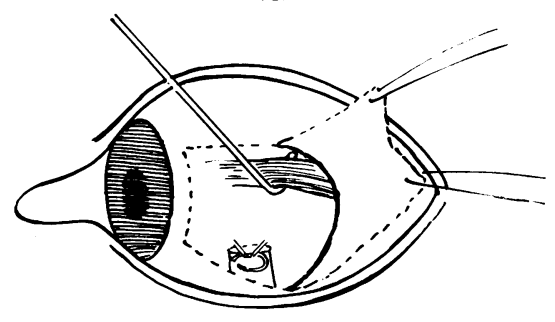

FIG. 3 The inferior oblique has been severed at its insertion. The fascial expansion to the region of the optic nerve can now be divided well clear of the globe.

FIG. 4 The inferior oblique has been attached at its new insertion. The conjunctiva is ready for closure.

The 6.o catgut conjunctival sutures are now completed at the limbus above and below, and additional sutures are inserted along the radial enlargement of the limbal incision.

The technique may easily be modified to permit operation upon the lateral rectus by making the conjunctival incision larger above, and the medial rectus may be operated on at the same time.

A similar approach may be utilized for a shortening operation of the inferior oblique. 


\section{Discussion}

Previous methods of inferior oblique recession have approached the insertion by blunt dissection. They have used rather complex methods of placing the recession, because of the difficulty of estimating the direction of action of the inferior oblique muscle and of finding its original site once the muscle is divided. As the insertion of the inferior oblique is muscular there is little sign of its site once it has been divided. The advantages of the method outlined here are as follows:

(I) The inferior oblique insertion is approached in the plane of the sclera, which allows easy identification and securing of its insertion. The fascial expansion from the inferior oblique to the lateral rectus insertion leads easily to the inferior oblique insertion.

(2) Insertion of the suture into the muscle and into its new insertion before dividing the existing insertion allows a graduated recession to be made in the line of action of the muscle quite simply without any special measuring device or geometrical calculation.

(3) Relative freedom from bleeding is noticeable, probably because the insertion of the inferior oblique is remote from its blood supply and severance at the insertion causes minimal bleeding.

(4) The safety rate is high. In a series of seventy cases there was no serious complication. In particular there was no evidence of any macular damage. Some care may be needed in placing the suture into the sclera at the new insertion as there is often vena vorticosa in this area.

(5) The amount of recession may be varied according to the deviation in the primar position:

(a) If less than $5^{\Delta}-5 \mathrm{~mm}$. recession should suffice.

(b) If between $5^{\Delta}$ and ${ }_{10}^{\Delta}-7 \mathrm{~mm}$. recession.

(c) If greater than $10^{\Delta}-$ Io or even $12 \mathrm{~mm}$. of recession may be done for a large vertical angle.

\section{Summary}

A simplified method of inferior oblique recession is described.

The advantages of this method include the ability to perform a graduated recession in the line of action of the muscle with a high degree of safety.

The method utilizes a limbal incision enlarged radially at its lower end. The inferior oblique insertion is approached in the plane of the sclera and a suture is placed into the muscle near its insertion. This suture is then placed at the new insertion in the line of action of the muscle, before the muscle is severed. This permits an accurate recession of the muscle to be made in the line of action of the muscle.

\section{References}

ANDERson, J. R. (I959) “Ocular Vertical Deviations and Treatment of Nystagmus”, pp. I 58-I6o. British Medical Association, London

BERKE, R. N. (1962) "Surgical Treatment of Hypertropia", in "Strabismus: Symposium of the New Orleans Academy of Ophthalmology", ed. J. M. Haik, pp. r9o-23o. Mosby, St. Louis 
BROWN, H. W. (1950) "Surgery of the Oblique Muscles", in "Strabismus Ophthalmic Symposium

(I)", ed. J. H. Allen, pp. 401-422. Mosby, St. Louis

colvin, c. (1950) Aust. and N.Z.F. Surg., 20, 59

Costenbader, F. D., and Kertesz, e. (1964) Amer. F. Ophthal., 57, 276

DUNLAP, E. A. (1960) Arch. Ophthal. (Chicago), 64, 167

DYER, J. A. (1962) Ibid., 68, 176

FFooks, o. O. (1962) Brit. orthopt. F., 19, 90

FINK, W. H. (I95I) "Surgery of the Oblique Muscles of the Eye", pp. 304-305. Mosby, St. Louis GUiBOR, G. P. (1949) Amer. F. Ophthal., 32, 221

LYLE, T. KEITH, and WYBAR, K. c. (1967) "Lyle and Jackson's Practical Orthoptics in the Treatment of Squint", $5^{\text {th }}$ ed., pp. 371 . Lewis, London

SCOBEe, R. G. (1952) “The Oculorotary Muscles", 2nd ed., pp. 472-473. Mosby, St. Louis

White, J. W. (1943) Amer. F. Ophthal., 26, 586 